\title{
The nuclear cofactor Receptor interacting protein-140 (RIP140) regulates the expression of genes involved in A $\beta$ generation
}

Katrin Blondrath ${ }^{1}$, Jennifer H. Steel ${ }^{2}$, Loukia Katsouri ${ }^{1}$, Miriam Ries ${ }^{1}$, Malcolm G. Parker ${ }^{2}$, Mark Christian ${ }^{3 *}$ and Magdalena Sastre ${ }^{1 *}$

1. Division of Brain Sciences, Imperial College, London W12 0NN, UK

2. Institute for Reproductive and Developmental Biology, Imperial College, London W12 0NN, UK

3. Division of Metabolic and Vascular Health, Warwick Medical School, University of Warwick, Coventry CV4 7AL, UK

Corresponding author: Magdalena Sastre, Imperial College London, Hammersmith Hospital, Du Cane Road, London W12 0NN, phone: +44-2075946673, fax: +44-2075946548, E-mail: m.sastre@imperial.ac.uk; Mark Christian, University of Warwick Coventry CV4 7AL, phone: +44-024 76 968585, fax: +44- Email:

M.Christian@warwick.ac.uk 


\section{Abstract}

The Receptor Interacting Protein 140 (RIP140) is a cofactor for several nuclear receptors and has been involved in the regulation of metabolic and inflammatory genes. We hypothesize that RIP140 may also affect A $\beta$ generation because it modulates the activity of transcription factors previously implicated in APP processing, such as PPAR $\gamma$. We found that the levels of RIP140 are reduced in AD post-mortem brains compared with healthy controls. In addition, in situ hybridization experiments revealed that RIP140 expression is enriched in the same brain areas involved in AD pathology, such as cortex and hippocampus. Furthermore, we provide evidence using cell lines and genetically modified mice that RIP140 is able to modulate the transcription of certain genes involved in AD pathology, such as BACE1 and GSK3. Consequently, we found that RIP140 overexpression reduced the generation of $A \beta$ in a neuroblastoma cell line by decreasing the transcription of BACE1 via a PPAR $\gamma$-dependent mechanism. The results of this study therefore provide molecular insights into common signalling pathways linking metabolic disease with AD.

\section{Highlights}

*RIP140 is expressed in human cortex and hippocampus and reduced in AD

*RIP140 knockout and transgenic mice show different expression of genes involved in AD.

*GSK3 and BACE1 levels are up-regulated in RIP140 knockout mice and reduced by RIP140 overexpression in cell lines.

*RIP140 transient transfection reduces A $\beta$ generation in a neuroblastoma cell line.

Key words: PPAR $\gamma$; Alzheimer's disease; RIP140; BACE1; GSK3; A $\beta$

Abbreviations: AD: Alzheimer's disease; APP: amyloid precursor protein; BACE1: $\beta$-APP cleaving enzyme; GSK3: Glycogen synthase kinase 3; PGC1- $\alpha$ : PPAR $\gamma$ coactivator-1 $\alpha$; PPAR $\gamma$ : Peroxisome proliferatoractivated receptor- $\gamma$; RIP140: Receptor Interacting Protein 140 


\section{Introduction}

Age-related diseases seem to share common underlying genetic mechanisms and pathways (Johnson et al., 2015); there is strong evidence for the association between metabolic disorders and neurodegenerative diseases with an inflammatory component, such as Alzheimer's disease (AD) (Sastre et al, 2006a; Sastre et al., 2011). Nuclear receptor signalling seems to play an important role linking energy metabolism and inflammatory processes (Glass and Oqawa, 2006). The Receptor interacting Protein 140 (RIP140) was identified 15 years ago as a cofactor for nuclear receptors and found to function as a co-repressor for a number of nuclear receptors that regulate metabolic pathways, including estrogen receptor-related receptors (ERRs), liver X receptor (LXR) and Peroxisome proliferator activated receptors (PPARs) (Leonardson et al., 2004; Seth et al, 2007; Christian et al., 2006). Subsequently RIP140 was also shown to act as co-activator of NFkB, Sp1 and AhR in macrophages thereby stimulating the expression of a number of inflammatory cytokines (Zschiedrich et al., 2008). Mice lacking RIP140 present some characteristic phenotypes, such as altered energy homeostasis and female infertility, which arise from the observation that RIP140 plays an essential role for ovulation (White et al., 2000). The generation of RIP140 deficient mice revealed that RIP140 is involved in glucose and lipid metabolism in adipocytes, muscle and liver tissue, presenting resistance to diet-induced obesity and increased clearance and insulin sensitivity (Powelka et al., 2006; Leonardsson et al., 2004; Herzog et al., 2007; Seth et al., 2007). Additionally, studies of not only RIP140 knockout but also RIP140 overexpressing transgenic mice have demonstrated roles for this cofactor in heart musculature (Fritah et al., 2010), macrophage activation (Zschiedrich et al., 2008), mammary gland (Nautiyal et al., 2013) and brain (Duclot et al., 2012).

The role of RIP140 in the brain is not fully understood. It has been demonstrated that changes in its expression have implications on cognition. A study conducted in the RIP140 knockout mice demonstrated that these mice suffer from memory and learning impairments and show an increased response to stress in comparison to wild type mice (Duclot et al., 2012). In addition, RIP140 levels seem to be highly expressed during neurodevelopmental stages and reduced during aging (Ghosh S, Thakur MK, 2008; Yuan et al, 2012; Katsouri et al., 2012). Interestingly, it was recently reported that in neurons, RIP140 contributes to a rapid suppression of the ER stress response and therefore provides protection against neuronal death (Feng et al., 2014). Importantly, RIP140 is a prominent cofactor for $\operatorname{PPAR} \gamma$, and we have previously reported that PPAR $\gamma$ 
activation, such as by treatment with TZDs and certain NSAIDs, reduces A $\beta$ in vitro and in animal models of AD by affecting BACE1 transcription (Heneka et al., 2005; Sastre et al, 2003, 2006b).

We hypothesize then that RIP140 affects $A \beta$ generation and/or degradation and therefore may have a role in the progression of AD. In this study, we investigated the relevance of RIP140 in AD using cell culture models as well as genetically modified mice. The results of this work provide molecular insights into the function of factors linking metabolic disease with AD and may offer opportunities for therapeutic intervention.

\section{Materials and Methods}

\section{$\underline{\text { Human postmortem samples }}$}

Human brains were obtained from routine autopsies at the Huddinge Brain Bank in accordance with the laws and the permission of the ethical committee. The control group included frontal-cortex from subjects who died either of non-neurological diseases or traffic accidents and had no history of long-term illness or dementia (76yrs $\pm 6: 4 \mathrm{~F}, 2 \mathrm{M}$ ). The sporadic AD group included the frontal-cortex samples from patients with clinically and pathologically confirmed $\mathrm{AD}(81 \mathrm{yrs} \pm 2: 5 \mathrm{~F}, 2 \mathrm{M})$. The frozen tissue was crudely fractionated to give a nuclear, membrane and cytosolic fraction. Samples were kept at $-80^{\circ} \mathrm{C}$ until used.

\section{Animals}

For this study RIP140 knockout (8 males and 3 females) of 9 months of age and RIP140 transgenic mice (5 male and 7 females) of 5 months of age and their corresponding wild-type littermates were used. This number of animals was used to allow enough statistical power was calculated according to our previous experience (Sastre et al., 2006). We confirmed this number is appropriate using InVivoStat, an R-based statistical package. Generation of the RIP140 knock out line was performed by homologous recombination in embryonic stem cells, replacing the RIP140 gene with a lacZ-neofusion gene cassette (IRES $\beta$ GEO), containing a ribosomal entry site, as previously described by White et al., in 2000. Mice used in this study had been backcrossed eight generations to C57BL/6J background.

RIP140 transgenic mice were generated by inserting human RIP140 (hRIP140; NRIP1 - Human Gene Nomenclature Database) in FVB/N background using a pCAGGS-hRIP construct (Fritah et al., 2010; Nautiyal et al., 2013). FVB/N wild-type (WT) littermates were used as controls.

Animals were maintained under standard conditions, with controlled light and temperature, and fed a chow diet ad libitum. Animals were anesthetized with sodium pentobarbital in a designed area in the morning and transcardially perfused with ice-cold phosphate-buffered saline (PBS) (0.1 M, pH 7.4). Brains were rapidly 
removed, and the right hemisphere was immersion fixed in $4 \%$ paraformaldehyde in PBS $(0.1 \mathrm{M}, \mathrm{pH} 7.4)$ for 48 hours and then cryoprotected in $20 \%$ sucrose in PBS (0.1 M, pH 7.4). The left hemispheres were dissected, snap frozen, and stored at $-80^{\circ} \mathrm{C}$ until protein isolation.

All animal experiments conformed to the British Home Office Regulations (Animal Scientific Procedures Act 1986).

\section{Cell lines, cell culture, and transient transfection.}

Mouse neuroblastoma N2a cells stably transfected with AßPP695 containing the Swedish mutation (AßPPsw, K595N/M596L) were obtained from G. Thinakaran (University of Chicago, Chicago, IL) and were cultured in 60\% DMEM with 40\% Opti-MEM and 5\% fetal bovine serum supplemented with $0.2 \mathrm{mg} / \mathrm{ml} \mathrm{G} 418$. Cells were incubated at $37^{\circ} \mathrm{C}$ in a $5 \% \mathrm{CO}_{2}$ atmosphere. Transfections were performed using Lipofectamine 2000 (Invitrogen) or FuGene (Roche) as described previously (Sastre et al., 2006) with $10 \mu \mathrm{g}$ RIP140 or RIP140 shRNA, mouse PPAR $\gamma$ cDNA (from Dr. Ron Evans, The Salk Institute for Biological Studies, San Diego, CA). For RIP140 siRNA (Genepharma), PPAR $\gamma$ siRNA and BACE1 siRNA (both from Dharmacon) we used $20 \mu \mathrm{M}$ per 6 well-plate. As controls we used empty plasmid and control siRNA. Cells were treated with 10-20 $\mu \mathrm{M}$ Pioglitazone (Tocris Bioscience) or DMSO overnight. 48h after transfection, cells were harvested. Transfection efficiency was determined by Western blot, immunofluorescence or qPCR.

\section{$\underline{\text { Western blotting }}$}

Cell lysates and brain homogenates were extracted with radioimmunoprecipitation assay buffer (1\% Triton X$100,1 \%$ sodium deoxycholate, $0.1 \%$ sodium dodecyl sulfate [SDS], $150 \mathrm{mM} \mathrm{NaCl}$, and $50 \mathrm{mM}$ Tris- $\mathrm{HCl}, \mathrm{pH}$ 7.2) supplemented with Roche Complete protease inhibitor and phosphatase inhibitor (PhosSTOP) cocktails. Equal amounts of protein $(20-100 \mu \mathrm{g})$ samples were separated in SDS-polyacrylamide gel electrophoresis (PAGE) gels, followed by immunoblotting with primary antibodies (listed in supporting information), and detected with horseradish peroxidase conjugated secondary antibody in 5\% non-fat dried milk in Tris-buffered saline with $0.05 \%$ Tween-20. Membranes were developed using ECL reagents (GE Amersham, UK) and using Hyperfilm ECL audioradiography film in an automated developer (Konica, SRX 101A). The intensity of the bands was quantified by densitometry using Image $\mathbf{J}$ software (National Institutes of Health) and normalized to $\beta$-Actin.

Determination of secreted APP $\alpha$ ectodomain and $A \beta$. 
Secreted APP- $\alpha$ (sAPP $\alpha)$ and A $\beta$ in the medium were measured by Western blotting after separation by $4-12 \%$ NuPAGE gels (Invitrogen) followed by transfer to nitrocellulose membranes and immunodetection with antibody 6E10 and the ECL system (Amersham Biosciences, Freiburg, Germany). The protein bands were scanned and quantified (NIH Image $\mathbf{J}$ analysis program) and results were corrected according to the protein concentration in cell lysates.

\section{Determination of $\beta$-secretase activity.}

The enzymatic activity of $\beta$-secretase was measured by a fluorimetric reaction (Abcam). The assay uses a secretase-specific peptide conjugated to two reporter molecules, EDANS and DABCYL. In the uncleaved form, the fluorescent signal from EDANS is quenched by the physical proximity of the DABCYL moiety. Cleavage of the peptide by $\beta$-secretase physically separates EDANS and DABCYL allowing for the release of a fluorescent signal. N2aSw cells were resuspended in $200 \mu \mathrm{l}$ of the "Extraction Buffer". $50 \mu$ l of the sample was incubated with $50 \mu \mathrm{l}$ of the $2 \mathrm{X}$ "Reaction Buffer" and $3 \mu \mathrm{l}$ of substrate at $37^{\circ} \mathrm{C}$ for $2 \mathrm{hrs}$ with mild shaking in the dark. The fluorescence was measured using a fluorimeter (Spectramax Gemini) using approximately 75 $\mu \mathrm{g}$ of protein lysate per well, with excitation between $335-355 \mathrm{~nm}$ and emission detection between 495-510nm. As positive control we used Active $\beta$-secretase and as negative control a $\beta$-secretase inhibitor provided by the supplier.

We also analysed the generation of the carboxy-terminus fragments (CTFs) in brain homogenates as measurement of secretase's activity. CTFs were determined by Western blotting after separation of samples in 4-12\% NuPAGE gels (Invitrogen) followed by transfer to nitrocellulose membranes and immunodetection with antibody R1-57. The protein bands were scanned and quantified (NIH Image J analysis program) and results were normalized to full length APP.

\section{Immunocytochemistry}

The subcellular localization of RIP140 and APP was detected in N2a cells overexpressing APPsw and RIP140 grown to $70 \%$ confluence on sterilised coverslips. Cells were washed once in sterile 1X PBS and then fixed and permeabilized in $100 \%$ methanol for 10 mins at $-20^{\circ} \mathrm{C}$. The cells were then rehydrated with PBS and blocked in $10 \%$ bovine serum albumin (BSA) made up in PBS for 10 minutes at RT. Cells were washed 3X in PBS. Primary antibodies were prepared in 1\% BSA in PBS. A monoclonal mouse anti RIP140 was used at 1/500 and full length APP was detected by R1-57 at 1/100. Cells were incubated with the primary for 1 hour at $37^{\circ} \mathrm{C}$ in a humid chamber to prevent coverslips from drying out. Secondary Anti-Rabbit Alexa Fluor $488 \AA$ 
(Invitrogen, US) and an anti-mouse Alexa Fluor 594® were used at 1/200 for $1 \mathrm{hr}$ at $37 \mathrm{C}$. The coverslips were mounted onto glass slides using Vectashield mounting medium with a DAPI counterstain (Vector Laboratories, Burlingame,CA) and observed under confocal microscope.

$\underline{\text { ELISA }}$

The levels of human A $\beta 1-40$ and A $\beta 1-42$ in the media of N2asw cells were determined using High Sensitivity Human Amyloid $\beta 40$ and $\beta 42$ ELISA kit (Millipore). The standard curve ranged $16 \mathrm{pg} / \mathrm{mL}-500 \mathrm{pg} / \mathrm{mL}$. Concentrations were quantified according to the manufacturer's instructions.

\section{$\underline{R N A}$ preparation, reverse transcription- $P C R$ and $q P C R$}

RNA extraction was performed using Trizol reagent (Sigma) and reverse-transcription quantitative-PCR analysis was performed using a 2 step method with an initial RT and subsequent real time cycling on a Strategene Mx3000p block cycler. Real time cycling was carried out with the Quantifast ${ }^{\circledR}$ SYBR green (Qiagen) and Quantiect® Primer assays (Qiagen) for mouse BACE1. Other primers used to measure mRNA levels of other genes are listed in table 1 (Supporting information). All genes were normalized to a housekeeping gene, which were in our case was GAPDH. A post melt-curve analysis revealed the absence of primer dimmers for all primer sets. For each repeat a calibration curve $(100,10$, and $1 \mathrm{ng})$ was produced for each transcript to ascertain the primer set efficiency and the cDNA input. The efficiency is described by the equation: $\mathrm{E}=10(-1 /$ slope $)$.

In addition, RT2-Profiler PCR array (Qiagen) was carried out in hippocampal mRNA extracts for analysing the expression of a focused panel of genes related to Alzheimer's Disease. The array includes genes that contribute to amyloid beta-peptide (A $\beta)$ generation, clearance, and degradation, as well as genes involved in amyloid beta-peptide $(\mathrm{A} \beta)$ signal transduction leading to neuronal toxicity and inflammation.

\section{Luciferase Assay.}

The luciferase reporter assay for BACE1 promoter activity was performed according to the instructions of the manufacturer (Promega). Briefly, the cells were transfected with 800 ng Luc-plasmid and 2ng CMV-RenillaPlasmid (1:400 ratio) for 24 well plate. $48 \mathrm{~h}$ after transfection the cells were harvested and resuspended in 200 $\mu l$ of lysis buffer. Equal amounts of proteins were used for the assay.

\section{$\underline{\beta \text {-Galactosidase staining }}$}

Brains were fixed in $2.5 \%$ methanol-free paraformaldehyde during $1 \mathrm{~h}$ at $4^{\circ} \mathrm{C}$. After three washes in cold phosphate buffer saline with $0.2 \mathrm{mM} \mathrm{MgCl} 2,0.02 \% \mathrm{NP}-40$ and $0.01 \%$ sodium deoxycholate, tissues were 
incubated in a LacZ staining solution (10 mM K3Fe(CN)6, $10 \mathrm{mM} \mathrm{K4Fe(CN)6,3H2O} \mathrm{and} 1.5 \mathrm{mg} / \mathrm{ml}$ X-Gal) overnight at $37{ }^{\circ} \mathrm{C}$ protected from light and postfixed in $4 \%$ methanol-free paraformaldehyde.

\section{$\underline{\text { In situ hybridization }}$}

An RNA probe for RIP140 exon 1b was transcribed from a cDNA template using a Megascript SP6 or T7 kit (Ambion), incorporating digoxigenin-11-UTP (Roche) (Nichol et al, 2006). Sections were deparaffinised, rehydrated and then permeabilised by digestion with proteinase K. Sections were fixed in $4 \%$ paraformaldehyde, washed and air dried before hybridisation. The probe was diluted between 1:50-1:100 with hybridisation buffer (50\% formamide, 5x SSC, 1x Denhardt's solution, 10\% dextran sulphate, and $100 \mu \mathrm{g} / \mathrm{ml}$ denatured herring sperm DNA) and $10 \mu 1$ of diluted probe was applied to each section and incubated in a humid chamber overnight at $55^{\circ} \mathrm{C}$. RNase pre-treated sections or sections receiving hybridisation buffer only or sense probes, were used as negative controls. Following the hybridisation step, the slides were washed to remove excess and non-specifically bound riboprobe. For detection of the hybridised probe, slides were incubated with an anti-digoxigenin-alkaline phosphatase conjugate (Roche).Alkaline phosphatase-labelled hybrids were detected using a solution of $337 \mu \mathrm{g} / \mathrm{ml}$ nitro blue tetrazolium (NBT, Roche), $175 \mu \mathrm{g} / \mathrm{ml}$ 5-bromo-4-chloro-3indolyl phosphate (BCIP, Roche) and $1 \mathrm{mM}$ levamisole. Slides were rinsed and mounted in aqueous mountant (Glycerol Gelatine, Sigma).

\section{Statistical Evaluation.}

Data were statistically analyzed by GraphPad Prism 5 by using Student's $t$ test or ANOVA followed by the Newman-Keuls multiple comparison test or the Dunnett post hoc test, depending on whether we were comparing different groups with the control group (Dunnett) or whether all pairs of columns were compared (Newman-Keuls multiple comparison).

\section{Results}

$\underline{\text { RIP140 expression is reduced in AD brain }}$

We have previously reported that the expression of PPAR $\gamma$ and its main co-activator PGC- $1 \alpha$ are reduced in the brain of AD patients (Sastre et al., 2006; Katsouri et al., 2011). We determined whether the expression of RIP140 was altered in AD patients, comparing brain samples from AD patients with age-matched healthy control brains. We performed immunoprecipitation/Western blotting experiments with antibody 6D7 against 
RIP140 in nuclear extracts from frontal cortex from 7 AD cases and 6 controls. The results indicate that RIP140 expression is reduced in $\mathrm{AD}$ patients compared to healthy controls (Fig. 1A).

\section{Distribution of RIP140 in the mouse brain}

We then explored the localization of RIP140 in the brain. In situ hybridisation was carried out in brain sections of a healthy human brain (Fig. 1B) and sagittal sections of wild-type mice, using a probe against exon 1b of RIP140. The results show that RIP140 is highly expressed in cortical areas, in particular in the hippocampus, frontal cortex as well as in the cerebellum (Fig. 2A).

Another way to determine the distribution of RIP140 was by performing $\beta$-Galactosidase staining to detect LacZ gene expression in sections of RIP140 knockout mice. Because RIP140 gene was replaced by the LacZ sequence in the generation of RIP140-KO animals, $\beta$-galactosidase transcription is driven by the RIP140 promoter and therefore mirrors the expression of the endogenous RIP140 gene in WT mice. LacZ staining confirmed the localisation of the RIP140 gene in cells from hippocampus and cortical areas of the brain (Figures 2B and 2C), two areas highly involved in AD pathology.

\section{RIP140 regulates the expression of genes involved in Alzheimer's disease}

Because RIP140 is a co-regulator for transcription factors implicated in AD (such as PPAR $\gamma$ and NFkB) and is expressed in key regions of the brain associated with the pathology, we performed a qPCR based array (Qiagen) specific for genes involved in $\mathrm{AD}$, using mRNA extracts from hippocampal tissue of two male mice lacking RIP140 and 2 matching wild- type controls.

The results illustrated in figure 3A show genes that are up-regulated in RIP140 KO mice (bars with values above the baseline) or down-regulated (values below the baseline) in comparison to wild-type expression of the gene. Genes of interest that appeared to be up-regulated in RIP140 null mice were ApoA1, Bace1, Bace2, Cdk5, Gap43, Igf2 and Mtap2 (green arrows) and genes down-regulated were ApoE, Gsk3ß and Ide (red arrows). Interestingly, many of these genes seem to be related to the insulin signalling pathway (Fig 3A). Additionally, we aimed to confirm these data by qPCR, increasing the number of animals per group, selecting the most interesting genes and adding some genes not present on the array but of relevance for $\mathrm{AD}$, such as Neprilysin and Mtap1. The results confirmed the up-regulations of genes such as Bace1, Cdk5, Mtap2, and Gap43 in RIP140 knockout brains and a reduction in the transcription levels of ApoE, compared to Wild-type mice (Fig. 3B). 
Furthermore, we analysed the expression of the same set of genes in the brains of RIP140 transgenic mice and their wild-type littermates. In contrast with the results obtained in the knockout, BACE1, Mtpa1 and Mtap2 mRNA values appeared reduced in RIP140 transgenics (Fig. 3C) when compared with wild-type mice. No significant changes were detected in other genes.

\section{$\underline{\text { RIP140 regulates the expression of GSK3 }}$}

An interesting gene that was found altered in the mRNA screening of RIP140 knockout brain was GSK3. This kinase has been involved in both tau phosphorylation and $\mathrm{A} \beta$ generation (Bhat et al., 2004). Two isoforms of GSK3 exist, GSK3 $\beta$ and GSK3 $\alpha$ and both versions are ubiquitously expressed but partially involved in different processes (Jope and Johnson, 2004). GSK3 is negatively regulated by kinases that directly phosphorylate a regulatory N-terminal serine of GSK3 [shown as Ser9 (S9) of GSK3b].(Jope and Johnson, 2004). We assessed the expression of both GSK3 isoforms as well as p-GSK3 by Western blot in the brains of RIP140 knockout and transgenic mice.

p-GSK3 $\beta$ levels were not significantly different between wild-type and RIP140 null and RIP140 transgenic mice (Fig. 4A). However, the expression of both GSK3 $\alpha$ and GSK3 $\beta$ isoforms were found increased in cortex of RIP140 knockout mice (Fig. 4A). In order to know whether GSK3 activity was also altered in the brain of RIP140 knockout and transgenic mice, we determined the expression of Axin2. Axin2 is a gene regulated by activation of the Wnt/ $\beta$-catenin pathway, which is modulated by GSK3 (Jho et al., 2002). Our results show a marked reduction of Axin2 mRNA in the cortex of RIP140 knockout mice and a non-significant increase in the brains of transgenic mice compared with wild-types (Figure 4B). These results are consistent with the increases in GSK3 expression found in RIP140 knockout mouse brains.

To confirm whether RIP140 affected GSK3 expression in neurons in vitro and whether this was mediated through a mechanism involving PPAR $\gamma$, we performed the same experiments in N2asw cells transfected with PPAR $\gamma$ siRNA. N2a cells stably expressing APPsw were transfected with human RIP140 cDNA tagged with V5. We found a decrease on p-GSK3 $\beta$ levels, probably due to a reduction in the expression of GSK3 $\beta$ in cells overexpressing RIP140 (Fig. 4C). However, this effect was not mediated through PPAR $\gamma$ since the values were not reversed by PPAR $\gamma$ knockdown (Fig. 4C). A down-regulation of GSK3 $\beta$ mRNA levels by RIP140 exogenous overexpression was also found when analysed by qPCR (Fig. 4D). The confirmation of the efficiency of transfection is shown in figures $5 \mathrm{~A}$ and $5 \mathrm{~B}$, by immunofluorescence experiments and also by 
Western blot with an antibody against V5. Therefore, RIP140 seems to repress the expression of GSK3 by regulating a transcription factor different of $\operatorname{PPAR} \gamma$.

\section{$\underline{\text { RIP140 affects } A \beta \text { generation by reducing } B A C E 1 \text { transcription }}$}

An additional gene that was found significantly altered in RIP140 knockout brains was BACE1. Therefore, we next evaluated the effect of exogenous RIP140 expression on the expression and activity of this enzyme. As mentioned previously, BACE1 transcription is regulated by nuclear receptors such as PPAR $\gamma$ or estrogen receptors, whose activity is controlled by RIP140. When transfecting a human construct of RIP140 into the neuronal N2aSw cell line we demonstrated that its localisation was exclusively nuclear (Fig.5A). Cells were also incubated with Pioglitazone $(20 \mu \mathrm{M})$ during $40 \mathrm{~h}$, since it has been described that RIP140 binds to PPAR $\gamma$ in ligand activated dependent manner. BACE1 protein expression was reduced by RIP140 overexpression by almost 50\% (Fig. 5C). Conversely, RIP140 knockdown by transfection of RIP140 siRNA resulted in an increase in BACE1 expression (Fig. 5D) and prevented the down-regulation of BACE1 levels by pioglitazone. To determine whether BACE1 activity was also decreased by RIP140, a fluorescence enzymatic assay for $\beta$ secretase was performed using a synthetic peptide containing the specific $\beta$-cleavage site, showing around $15 \%$ decrease in $\beta$-secretase activity in cells transfected with RIP140 or PPAR $\gamma$ cDNAs (Fig. 5E).

Changes in BACE1 expression were paralleled with alterations in BACE1 mRNA levels (Fig. 5F). As observed above, cells transfected with RIP140 siRNA showed increased BACE1 mRNA levels (Fig. 5F). In addition, we examined whether BACE1 promoter activity was modulated by RIP140 using a Firefly luciferase reporter gene driven by the rat BACE1 promoter transfected in N2asw cells. We observed a reduction in the activity of the BACE1 promoter in cells transfected with RIP140 and an increase with RIP140 knockdown (Fig. 5G).

In order to determine whether the effects of RIP140 on BACE1 transcription were mediated through activation of PPAR $\gamma$, we performed Western blotting for BACE1 in cells transfected with PPAR $\gamma$ siRNA. The results on Figure $5 \mathrm{H}$ show that the reduction in the levels of BACE1 following RIP140 transfection were restored to control levels after RIP140 exogenous expression in PPAR $\gamma$ knockdown cells. These data suggest that RIP140 represses BACE1 transcription by acting as a cofactor for PPAR $\gamma$.

In line with this, our in vitro results in N2asw cells coincided with in vivo data obtained in brain homogenates of RIP140 transgenic mice, which showed a significant reduction of BACE1 expression compared to wildtype animals (Fig. 5I). Furthermore, we found a strong increase in total CTFs in the knockout brain 
homogenates compared to wild-type controls (Figure S1A), indicating a reduction in $\beta$-secretase activity, with no changes in the transgenic mice.

Because BACE1 is a key enzyme for A $\beta$ generation, we next examined whether RIP140 was able to alter the levels of A $\beta$ in N2asw cells. Under these conditions, cells overexpressing RIP140 and simultaneously activated with Pioglitazone showed a $24 \%$ reduction on secreted A $\beta$, in particular the A 342 subtype (Fig. 6A and 6B). This effect was not due to a decrease in full length APP (Fig. 6C) or in the cleavage by $\alpha$-secretase, as levels of soluble APP $\alpha$ were unchanged by the treatment (Fig. 6C).

\section{Discussion}

Epidemiological studies have indicated a link between metabolic diseases such as type 2 diabetes and Alzheimer's disease $(\mathrm{AD})$, with the risk of incidence $65 \%$ higher in individuals with diabetes mellitus than in those without (Arvanitakis et al, 2004). The mechanisms mediating these effects are not clear, but it has been hypothesized that insulin resistance (IR) and brain glucose deprivation impair brain function. IR and type-2 diabetes involve a state of chronic inflammation characterized by abnormal cytokine production, increased acute-phase reactants and other mediators, and the activation of a network of inflammatory signalling pathways (Hotamisligil, 2006), which could lead to higher propensity to develop AD or to exacerbate AD symptoms. Both PPAR $\gamma$ and its cofactor RIP140 have been implicated in the control of insulin sensitivity. The role of PPAR $\gamma$ is supported by the fact that several familial mutations in PPAR $\gamma$ lead to severe IR and diabetes mellitus (Barroso et al, 1998). Furthermore, mice deficient for PPAR $\gamma$ in skeletal muscle have significant whole body IR (Hevener et al, 2003). The PPAR $\gamma$ Pro12Ala polymorphism, which is associated with an increased risk of type 2 diabetes (Altshuler et al., 2000), has been found to influence plasma 24S-hydroxycholesterol/cholesterol ratios in AD patients (Sauder et al., 2005). In addition, PPAR $\gamma$ activators such as TZDs are widely used to increase peripheral insulin sensitivity (Wagstaff and Goa, 2002). These data suggest the possibility of a common genetic propensity for AD and IR. The importance of RIP140 in these signalling pathways was confirmed by examining the phenotype of RIP140 null mice which store markedly less triglyceride in white adipose tissue and exhibit protection from hepatic steatosis, resistance to diet-induced obesity and increased clearance and insulin sensitivity (Leonardsson et al., 2004; Powelka et al., 2006). Whole-body RIP140 knockout animals are lean and maintain insulin sensitivity, suggesting that RIP140 globally promotes fat accumulation and insulin resistance (Leonardsson et al., 2004; Powelka et al., 2006). Therefore, our initial 
interest was to explore the function of a metabolic modulator such as RIP140 in the brain and whether RIP140 affected the progression of neurodegenerative diseases like AD.

In this study we found that indeed RIP140 knockout brains present alterations in the transcription of genes linking AD with the insulin pathway, such as GSK3 and IGF2. As indicated previously, RIP140 has been found to function as a co-repressor for nuclear receptors that regulate metabolic pathways (Leonardson et al., 2004; Seth et al, 2007; Christian et al., 2006) but can also act as co-activator for transcription factors regulating inflammatory genes and cell proliferation such as NFkB (Zschiedrich et al., 2008; Nautiyal et. al, 2010). We found that RIP140 represses BACE1 transcription by a mechanism mediated by PPAR $\gamma$. The reduction in BACE1 transcription observed by overexpression of RIP140 coincides with previous results in cells transfected with the transcriptional regulator PGC-1 $\alpha$ (Katsouri et al., 2011; Gong et al., 2010; Wang et al 2013) or with PPAR $\gamma$ cDNA or by incubation with PPAR $\gamma$ agonists (Sastre et al, 2003, 2006b). The specificity of the effect of the PPAR $\gamma$ activators on BACE1 was confirmed in PPAR $\gamma$ knockout cells and in N2asw cells transfected with PPAR $\gamma$ siRNA, where these drugs did not affect BACE1 transcription (Sastre et al., 2006b). Our new data show that pioglitazone did not alter BACE1 expression in cells transfected with RIP140 siRNA (Figure 5D), thereby demonstrating that the effect of pioglitazone on BACE1 transcription seems to be mediated via RIP140 regulation of PPAR $\gamma$. Therefore, our results show that RIP140 binds to PPAR $\gamma$ in a ligand-activated dependent manner, leading to lower BACE1 transcription and subsequently reduced A $\beta$ generation (see schematic summary in Fig. S1B).

Another important gene regulated by RIP140 is GSK3. GSK3 activity is increased in the frontal cortex of AD patients and its expression is up-regulated in the hippocampus (Blalock et al. 2004). It co-localises with degenerating neurites and NFTs (Yamaguchi et al. 1996; Pei et al. 1997) and active GSK3 appears in neurons with pre-tangle changes (Pei et al. 1999). GSK3 is not only important for regulating Tau pathology but also A $\beta$ generation; recently our group demonstrated that GSK3 inhibition promotes lysosomal biogenesis and autophagic degradation of the APP (Parr et al., 2012) and the transcription of BACE1 through the Wnt/ $\beta$ catenin pathway (Parr et al., 2015).

We found that the frontal cortex of RIP140 knockout mice expressed elevated levels of GSK3- $\alpha$ and GSK3- $\beta$ compared to wild-type mice and reduced transcription of the Wnt target gene Axin2. Conversely, in vitro experiments carried out in N2asw cells seem to indicate that RIP140 overexpression reduces the levels of GSK3 mRNA, therefore indicating that RIP140 represses its transcription. It would be thus interesting to 
determine whether the GSK3 promoter contains consensus binding sites for transcription factors regulated by RIP140. This effect does not seem to be mediated through PPAR $\gamma$, since treatment of N2asw cells with PPAR $\gamma$ activators such as pioglitazone did not affect GSK3 expression (data do not shown) and PPAR $\gamma$ knockdown did not reverse GSK3 down-regulation by RIP140. It is worth noting that RIP140 could modulate transcriptional initiation at regulated promoters by a variety of mechanisms, including histone acetylation and chromatin remodelling (Kiskinis et al, 2007; Katsouri et al., 2012), and would be attractive to investigate in the future if this is the case for GSK3 regulation.

An alternative interpretation for the alterations on GSK3 expression may be found in the effects of the insulin signalling pathway on GSK3. Impairment of insulin signalling in the brain has been linked to tau phosphorylation. As mentioned before, RIP140 null mice exhibit high insulin sensitivity resulting in lower insulin plasma level due to their lower fat body content and higher insulin degradation. Insulin signalling activates the PI13-kinase which activates Akt8 a factor known to phosphorylate GSK3 $\alpha$ and $\beta$ at two serine residues (Saltiel and Kahn 2001; Lizcano and Alessi 2002). This serine phosphorylation leads to prevention of the enzymatic activity of GSK3. In fact, neuronal insulin receptor knockout mice present reduced pGSK3 levels (which is less active) and increased tau hyperphosphorylation (Schubert et al., 2004). This could also mean that regulations of GSK3 expression in our mouse model could be consequence of whole body RIP140 knockout on the insulin pathway rather than a transcriptional regulatory effect of RIP140 on GSK3 in the brain.

\section{Conclusions}

Overall, our study provides evidence for the protective effects of RIP140 in AD. The observation of reduced RIP140 levels in AD patients further support RIP140 down-regulation favouring disease progression. Therefore, therapies developed towards increasing RIP140 expression in the brain would be effective for treating AD. RIP140 expression could be pharmacologically manipulated by activating a number of nuclear receptors including steroids/retinoids or alternatively, by delivering its cDNA into the brain using gene therapy. In line with this, recently we have successfully administered PGC1 $\alpha$ via lentiviral injection, another PPAR $\gamma$ activator, in the cortex and hippocampus of transgenic APP23 mice (Katsouri et al, 2015 unpublished observations).

\section{Acknowledgements}

This work was funded by a PhD studentship from the Alzheimer's research UK (ART-PhD2011-16). 
We would like to thank Dr. Amy Birch for helpful advice on ELISA technique and the Swedish Brain Bank for the donation of the human brains used in the present study. We are also grateful to Dr. Gopal Thinakaran (University of Chicago) for N2asw cells and Dr. Steffen Rossner (University Leipzig) for the BACE1 promoter complementary DNA. We would like to dedicate this study to the memory of Jamie Graham, who raised funds to make this work possible.

\section{References}

Altshuler D, Hirschhorn JN, Klannemark M, Lindgren CM, Vohl MC, Nemesh J, Lane CR, Schaffner SF, Bolk S, Brewer C, Tuomi T, Gaudet D, Hudson TJ, Daly M, Groop L, Lander ES. The common PPARgamma Pro12Ala polymorphism is associated with decreased risk of type 2 diabetes. Nat Genet. 2000; 26:76-80.

Arvanitakis Z, Wilson RS, Bienias JL, Evans DA, Bennett DA. Diabetes mellitus and risk of Alzheimer disease and decline in cognitive function. Arch Neurol 2004; 61: 661-6.

Bhat RV, Budd Haeberlein SL, Avila J. Glycogen synthase kinase 3: a drug target for CNS therapies. J Neurochem. 2004; 89:1313-7.

Barroso I, Gurnell M, Crowley VE, Agostini M, Schwabe JW, Soos MA, Maslen GL, Williams TD, Lewis H, Schafer AJ, Chatterjee VK, O'Rahilly S. Dominant negative mutations in human PPARgamma associated with severe insulin resistance, diabetes mellitus and hypertension. Nature 1999; 402:880-3.

Blalock EM, Geddes JW, Chen KC, Porter NM, Markesbery WR, Landfield PW. Incipient Alzheimer's disease: microarray correlation analyses reveal major transcriptional and tumour suppressor responses. Proc Natl Acad Sci U S A 2004; 101:2173-2178.

Christian M, White R, Parker MG. Metabolic regulation by the nuclear receptor corepressor RIP140. Trends Endocrinol Metab. 2006; 17:243-50.

Debevec D, Christian M, Morganstein D, Seth A, Herzog B, Parker M, White R. Receptor interacting protein 140 regulates expression of uncoupling protein 1 in adipocytes through specific peroxisome proliferator activated receptor isoforms and estrogen-related receptor alpha. Mol Endocrinol. 2007;7:1581-92.

Duclot F, Lapierre M, Fritsch S, White R, Parker MG, Maurice T, Cavaillès V. Cognitive impairments in adult mice with constitutive inactivation of RIP140 gene expression. Genes Brain Behav. 2012; 11: 69-78.

Feng X, Krogh KA, Wu CY, Lin YW, Tsai HC, Thayer SA, Wei LN. Receptor interacting protein 140 attenuates endoplasmic reticulum stress in neurons and protects against cell death. Nat Commun. 2014;5:4487. 
Fritah A, Christian M, Parker MG. The metabolic coregulator RIP140: an update Am J Physiol Endocrinol Metab. 2010; 299: E335-40.

Glass CK, Ogawa S. Combinatorial roles of nuclear receptors in inflammation and immunity. Nat Rev Immunol. 2006; 6:44-55.

Gong B, Chen F, Pan Y, Arrieta-Cruz I, Yoshida Y, Haroutunian V, Pasinetti GM. SCFFbx2-E3-ligasemediated degradation of BACE1 attenuates Alzheimer's disease amyloidosis and improves synaptic function. Aging Cell 2010; 9: 1018-31.

Ghosh S, Thakur MK. Tissue-specific expression of receptor-interacting protein in aging mouse. Age (Dordr) 2008; 30: 237-24.

Hallberg M, Morganstein DL, Kiskinis E, Shah K, Kralli A, Dilworth SM, White R, Parker MG, Christian M. A functional interaction between RIP140 and PGC-1alpha regulates the expression of the lipid droplet protein CIDEA. Mol Cell Biol. 2008; 28: 6785-95.

Heneka MT, Sastre M, Dumitrescu-Ozimek L, Hanke A, Dewachter I, Kuiperi C, O'banion K, Klockgether T, Van Leuven F, Landreth GE. Acute treatment with the PPAR $\gamma$ agonist pioglitazone and ibuprofen reduces glial inflammation and A $\beta 1-42$ levels in APPV717I transgenic mice. Brain 2005; 128:1442-1453.

Herzog B, Hallberg M, Seth A, Woods A, White R, Parker MG. The nuclear receptor cofactor, receptorinteracting protein 140 , is required for the regulation of hepatic lipid and glucose metabolism by liver X receptor. Mol Endocrinol 2007: 21: 2687-97.

Hevener AL, He W, Barak Y, Le J, Bandyopadhyay G, Olson P, Wilkes J, Evans RM, Olefsky J. Musclespecific Pparg deletion causes insulin resistance. Nat Med. 2003; 9: 1491-7.

Hotamisligil GS. Inflammation and metabolic disorders. Nature 2006; 444: 860-7.

Jho EH, Zhang T, Domon C, Joo CK, Freund JN, Costantini F. Wnt/beta-catenin/Tcf signaling induces the transcription of Axin2, a negative regulator of the signaling pathway. Mol Cell Biol. 2002; 22:1172-83.

Johnson SC, Dong X, Vijg J, Suh Y. Genetic evidence for common pathways in human age-related diseases. Aging Cell 2015;14: 809-17.

Jope RS, Johnson GV. The glamour and gloom of glycogen synthase kinase-3. Trends Biochem Sci 2004; 29: 95-102.

Katsouri L, Parr CJC, Bogdanovic N, Sastre M. PPAR $\gamma$ co-activator-1 $\alpha$ (PGC1 $\alpha$ ) decreases A $\beta$ generation through a PPAR $\gamma$-dependent mechanism. J. Alz Dis 2011; 25: 151-162. 
Katsouri L, Blondrath K, Sastre M. Peroxisome proliferator-activated receptor- $\gamma$ cofactors in neurodegeneration. IUBMB Life 2012; 64: 958-64.

Kiskinis E, Hallberg M, Christian M, Olofsson M, Dilworth SM, White R, Parker MG. RIP140 directs histone and DNA methylation to silence Ucp1 expression in white adipocytes. EMBO J. 2007; 26: 4831-40.

Leonardsson G, Steel JH, Christian M, Pocock V, Milligan S, Bell J, So PW. Medina-Gomez G, Vidal-Puig A, White R, Parker MG. Nuclear receptor corepressor RIP140 regulates fat accumulation. Proc Natl Acad Sci U S A. $2004 ; 101: 8437-42$.

Lizcano JM, Alessi DR. The insulin signalling pathway. Curr Biol. 2002; 12: R236-8.

Nautiyal J, Steel JH, Mane MR, Oduwole O, Poliandri A, Alexi X, Wood N, Poutanen M, Zwart W, Stingl J, Parker MG. The transcriptional co-factor RIP140 regulates mammary gland development by promoting the generation of key mitogenic signals. Development 2013; 140:1079-89.

Nichol D, Christian M, Steel JH, White R, Parker MG. RIP140 expression is stimulated by estrogen-related receptor- $\alpha$ during adipogenesis. J. Biol. Chem. 2006; 281:32140-32147.

Parr C, Carzaniga R, Gentleman SM, Van Leuven F, Walter J, Sastre M. Glycogen synthase kinase 3 inhibition promotes lysosomal biogenesis and autophagic degradation of the amyloid- $\beta$ precursor protein. Mol Cell Biol. 2012; 32: 4410-8.

Parr C, Mirzaei N, Christian M, Sastre M. Activation of the Wnt/ $\beta$-catenin pathway represses the transcription of the $\beta$-amyloid precursor protein cleaving enzyme (BACE1) via binding of T-cell factor-4 to BACE1 promoter. FASEB J 2015;:29:623-35.

Pei JJ, Tanaka T, Tung YC, Braak E, Iqbal K, Grundke-Iqbal I. Distribution, levels, and activity of glycogen synthase kinase-3 in the Alzheimer disease brain. J Neuropathol Exp Neurol 1997; 56: 70-78.

Pei JJ, Braak E, Braak H, Grundke-Iqbal I, Iqbal K, Winblad B, Cowburn RF. Distribution of active glycogen synthase kinase 3beta (GSK-3beta) in brains staged for Alzheimer disease neurofibrillary changes. J Neuropathol Exp Neurol. 1999;58: 1010-9.

Powelka AM, Seth A, Virbasius JV, Kiskinis E, Nicoloro SM, Guilherme A, Tang X, Straubhaar J, Cherniack AD, Parker MG, Czech MP. Suppression of oxidative metabolism and mitochondrial biogenesis by the transcriptional corepressor RIP140 in mouse adipocytes. J Clin Invest. 2006; 116: 125-36.

Qin W, Haroutunian V, Katsel P, Cardozo CP, Ho L, et al. PGC-1alpha expression decreases in the Alzheimer disease brain as a function of dementia. Arch. Neurol. 2009; 66: 352-361. 
Saltiel AR, Kahn CR. Insulin signalling and the regulation of glucose and lipid metabolism. Nature 2001; 414: 799-806.

Sastre M, Dewachter I, Landreth GE, Willson TM, Klockgether T, van Leuven F, Heneka MT. Nonsteroidal anti-inflammatory drugs and peroxisome proliferator-activated receptor- $\gamma$ agonists modulate immunostimulated processing of amyloid precursor protein through regulation of $\beta$-secretase. J. Neurosci 2003; 23: 9796-9804.

Sastre M, Klockgether T, Heneka MT. Contribution of inflammatory processes to Alzheimer's disease: molecular mechanisms. Int. J. Dev. Neurosci. 2006; 24: 167-76.

Sastre M, Dewachter I, Rossner S, Bogdanovic N, Rosen E, Borghgraef P, Evert BO, Dumitrescu-Ozimek L, Thal DR, Landreth G, Walter J, Klockgether T, van Leuven F, Heneka MT. Nonsteroidal anti-inflammatory drugs repress beta-secretase gene promoter activity by the activation of PPARgamma. Proc. Natl. Acad. Sci. $2006 b ; 103: 443-8$.

Sastre M, Richardson J, Gentleman SM, Brooks D. Inflammatory risk factors and pathologies associated with Alzheimer's disease. Current Alzheimer's Res 2011; 8: 132-41.

Sauder S, Kölsch H, Lütjohann D, Schulz A, von Bergmann K, Maier W, Heun R. Influence of peroxisome proliferator-activated receptor gamma gene polymorphism on 24S-hydroxycholesterol levels in Alzheimer's patients. J Neural Transm. 2005; 112:1381-9.

Seth A, Steel JH, Nichol D, Pocock V, Kumaran MK, Fritah A, Mobberley M, Ryder TA, Rowlerson A, Scott J, Poutanen M, White R, Parker M. The transcriptional corepressor RIP140 regulates oxidative metabolism in skeletal muscle. Cell Metab (2007); 6:236-45.

Schubert M, Gautam D, Surjo D, Ueki K, Baudler S, Schubert D, Kondo T, Alber J, Galldiks N, Küstermann E, Arndt S, Jacobs AH, Krone W, Kahn CR, Brüning JC. Role for neuronal insulin resistance in neurodegenerative diseases. Proc Natl Acad Sci U S A. 2004; 101: 3100-5.

Wagstaff AJ1, Goa KL. Spotlight on rosiglitazone in the management of type 2 diabetes mellitus. Treat Endocrinol 2002; 1: 411-4.

Wang R, Li JJ, Diao S, Kwak YD, Liu L, Zhi L, Büeler H, Bhat NR, Williams RW, Park EA, Liao FF. Metabolic stress modulates Alzheimer's $\beta$-secretase gene transcription via SIRT1-PPAR $\gamma$-PGC-1 in neurons. Cell Metab 2013;.17: 685-94. 
White R, Leonardsson G, Rosewell I, Ann Jacobs M, Milligan S, Parker M. The nuclear receptor co-repressor nrip1 (RIP140) is essential for female fertility. Nat Med 2000; 6; 1368-74.

Yuan R, Meng Q, Nautiyal J, Flurkey K, Tsaih S-W, Krier R, Parker MG, Harrison DE, Paigen B. Genetic coregulation of age of female sexual maturation and lifespan through circulating IGF1 among inbred mouse strains. Proc Natl Acad Sci U S A. 2012; 109: 8224-8229.

Zschiedrich I, Hardeland U, Krones-Herzig A, Berriel Diaz M, Vegiopoulos A, Müggenburg J, Sombroek D, Hofmann TG, Zawatzky R, Yu X, Gretz N, Christian M, White R, Parker MG, Herzig S. Coactivator function of RIP140 for NFkappaB/RelA-dependent cytokine gene expression. Blood 2008; 112:264-76.

\section{Figure legends}

Figure 1. RIP140 is decreased in AD post-mortem brains. A, Representative Western blot and quantification of RIP140 levels. $\beta$-actin was used as control for protein loading, $n=6-7$ subjects per group. Values are expressed as mean $\pm \mathrm{SEM} ;{ }^{*} \mathrm{P}<0.05$, Student's $\mathrm{t}$ test. $\boldsymbol{B}$, In situ hybridisation in cortex, using specific primer designed for RIP140 transcript show specific RIP140 labelling in human brain.

Figure 2. Distribution of RIP140 in the mouse brain. $\boldsymbol{A}$, In situ hybridisation, using specific primer designed for RIP140 transcript show specific RIP140 labelling in the brain, especially within the hippocampus and frontal cortex areas. The cerebellum and caudate are also enriched in RIP140. $\boldsymbol{B}, \beta$-Galactosidase staining indicates LacZ expression in the RIP140 RIP140 null brain, showing high levels of expression in the dentate gyrus and cerebral cortex. $\boldsymbol{C}$, In situ hybridization and $\beta$-Galactosidase in the same section of the cortex, shows co-localization in the same cells. Scale bars $=100 \mu \mathrm{m}$.

Figure 3. RIP140 regulates the expression of genes involved in Alzheimer's disease. A, Results obtained from $\mathrm{RT}^{2}$ Profiler PCR array focused on genes involved in AD was used to compare the profile of hippocampal mRNA samples of 2 months old RIP140 knockout and of wild-type mice. Differences are expressed in fold change to the baseline 1. Green arrows highlight genes exhibiting up-regulation. Red arrows show genes downregulated in RIP140 knockout mice. $\boldsymbol{B}$, mRNA hippocampal levels of the selected genes exhibiting up- and down-regulation in the screening shown above were further analysed in a larger number of RIP140 knockout mice (9 months old), showing significant differences compared with wild-type mice ( $n=4-6$ animals per group). $\boldsymbol{C}$, The same set of genes were analysed in mRNA extracts from cortex of 5 m.o. RIP140 transgenic mice, showing opposite effects ( $n=3-5$ animals per group). Values shown in graphs represent the mean value \pm SEM 
and are expressed as a fold change in comparison to the normalized wild-type control. Statistical analysis included student's t-test $* \mathrm{P}<0.05, * * \mathrm{P}<0.01, * * * \mathrm{P}<001$.

Figure 4. RIP140 regulates GSK3 expression. A, Representative Western blots and quantification of GSK3 subtypes ( $\alpha$ and $\beta$ ) and phosphorylated S9 GSK3 protein levels in cortex of RIP140 knockout and transgenic mice with their respective controls ( $\mathrm{n}=4-5$ animals per group). $\boldsymbol{B}$, Quantification of Axin2 mRNA levels in cortex of RIP140 knockout and transgenic mice with their respective controls (n=4-5 animals per group). $C$, Representative Western blot and quantification of GSK3 $\alpha$ and $\beta$ as well as phosphorylated S9 GSK3 protein expression in N2asw cells transfected with RIP140 and/or PPAR $\gamma$ siRNA show that the effect is independent on PPAR $\gamma$ expression ( $\mathrm{n}=10-12$ samples per group). $\boldsymbol{D}$, Quantification of GSK3 $\beta$ mRNA expression in N2asw cells overexpressing RIP140 cDNA with or without $20 \mu \mathrm{M}$ Pioglitazone (pio). Values shown in graphs represent the mean value \pm SEM and are expressed as a percentage change in comparison to the normalized wild-type control or fold change of control. Statistical analysis included student's t-test or one-way ANOVA followed by Dunnett's or Newman-Keuls Multiple Comparison Test. *P<0.05, **P<0.01.

Figure 5. RIP140 reduces BACE1 expression. $\boldsymbol{A}$, Immunofluorescence labelling using the 6D7 antibody against RIP140 protein (green) shows its cellular localisation, strictly restricted to the cell nucleus. The 6E10 antibody was used to detect full length APP (red), showing its distribution in plasma membrane and cytoplasm. DAPI (blue) was used to stain the nucleus of the cells. $\boldsymbol{B}$, Representative Western blot showing the efficiency of transfection with RIP140 cDNA using antibody against V5. C, Representative Western blots and quantification of BACE1 in N2asw cells shows a reduction in cells expressing RIP140 with vehicle or incubated with $20 \mu \mathrm{M}$ pioglitazone (n=4-5 samples per group). D, Representative Western blots and quantification of BACE1 in N2asw cells shows a reduction in cells incubated with $10 \mu \mathrm{M}$ pioglitazone and an increase in cells transfected with RIP140 siRNA (n=9-12 samples per group). $\boldsymbol{E}$, Quantification of enzymatic $\beta$-secretase activity using a fluorimetric assay shows a reduction in N2asw cells transfected with RIP140 or PPAR $\gamma$ cDNAs ( $\mathrm{n}=4$ samples per group). $\boldsymbol{F}$, Quantification of BACE1 mRNA in N2asw cells transfected with RIP140 cDNA or with RIP140 siRNA shows the opposite effects of both treatments ( $\mathrm{n}=6-9$ samples per group). $\boldsymbol{G}$, Luciferase activities of a $1.5-\mathrm{kb}$ BACE1 promoter/luciferase reporter construct transfected in N2a cells shows similar changes that were observed in BACE1 mRNA with the same conditions ( $\mathrm{n}=5-8$ samples per group). H, Representative Western blot and quantification of BACE1 expression in N2asw transfected with siRNA for PPAR $\gamma$ shows that the effect of RIP140 is reversed when PPAR $\gamma$ is knock-down ( $\mathrm{n}=8$ samples per 
group). I, Representative Western blot and quantification of BACE1 in the cortex shows a reduction in RIP140 transgenic mice ( $n=3-4$ animals per group). Values shown in graphs represent the mean value \pm SEM and are expressed as a percentage change in comparison to the normalized wild-type control or fold change of control. Statistical analysis included student's t-test or one-way ANOVA followed by Dunnett's or Newman-Keuls Multiple Comparison Test $* \mathrm{P}<0.05, * * \mathrm{P}<0.01, * * * \mathrm{P}<001$.

Figure 6. RIP140 exogenous expression reduces A $\beta$ levels in N2asw cells. $\boldsymbol{A}$, Representative Western blot and quantification of $A \beta$ in N2asw cells with $6 \mathrm{E} 10$ antibody shows reduced expression with the combination of RIP140 and $20 \mu \mathrm{M}$ pioglitazone (pio), (n=6-7 samples per group). B, Quantification of $\mathrm{A} \beta 40$ and $\mathrm{A} \beta 42$ subtypes by ELISA shows also a reduction of A $\beta 42$ in the same conditions (n=3-4 samples per group). $\boldsymbol{C}$, Representative Western blots and quantification of full length APP and soluble APP $\alpha$ in the same cells show no significant differences with the treatment ( $\mathrm{n}=5-11$ samples per group). Values shown in graphs represent the mean value \pm SEM and are expressed as a percentage change in comparison to the normalized wild-type control. Statistical analysis included one-way ANOVA followed by Dunnett's or Newman-Keuls Multiple Comparison Test $* \mathrm{P}<0.05$. 